\title{
Interactive comment on "Climate reconstructions based on GDGT and pollen surface datasets from Mongolia and Siberia: calibrations and applicability to extremely cold-dry environments over the Late Holocene" by Lucas Dugerdil et al.
}

\section{Anonymous Referee \#2}

Received and published: 1 February 2021

This study focuses on the calibration of proxy-climate relationships for pollen and GDGTs by comparing large published Eurasian calibrations with a set of 49 new surface samples. These calibrations are cross-validated by an independent dataset of top-core samples and then applied to two Late Holocene paleosequences from the Mongolian Altai and the Qaidam basin. GDGTs are relatively new proxies for reconstructing environmental conditions and any studies on calibrating modern datasets relative to climate data is very important. Along those lines, this work is interesting from a methodological point of view. However, the choice of paleodata for the application of the 
results obtained in the calibration is not correct: none of the paleo records does belong to the territory of the Mongolian Plateau described in the paper. Another disadvantage is that the data on pollen and on GDGTs were obtained from different paleosequences. Of course, not much data is currently available on GDGTs from Mongolia. Therefore, we will not consider this a shortcoming of the study, but we will consider it a consequence of the little research of the territory. However, pollen data from Mongolia are abundant. The next point is the definition of the study area. The map shows the entirety of Mongolia, with the Mongolian Plateau not highlighted. Part of the locations is near Lake Baikal (the authors call it the Siberian Basin). First of all, there is no Siberian Basin and there are mountains around Baikal. According to the map, samples were taken only along the Angara River, where the height is about $700 \mathrm{~m}$ asl. This location is only a minor point in the huge territory of Siberia. I propose to work out the geography of the study. Try to prove that the results of the calibration of your samples taken from the Angara and then the transect to the south can really be applied to the sites located in the Mongolian Altai and Qaidam. The ideal would have been to choose paleosites within your transect. At least try to explain why this is not being done. I also suggest adding South Siberia or Baikal area in the title instead of Siberia.

Specific comments Lines 14-15: "(3) even if local calibrations suffer from reduced amplitude of climatic parameter due to local homogeneity, they better reflect 15 actual climate than the global ones by reducing the limits for saturation impact," This statement is pretty obvious without many pages of statistics. Lines 65-66: "Environmental drivers are linked to climate parameters (Weijers et al., 2007b), soil typology and vegetation cover (Davtian et al., 2016), which in turn imply land cover and land use" I don't understand to what link this statement. To BrGDGT? Line 75: "CBT and MBT indexes". What is this? Abbreviations appear for the first time, they must be deciphered. Lines 76-78: "the 5-methyl correlates mainly with temperature (Naafs et al., 2017a), while 6 and 7methyl seem to react to moisture and $\mathrm{pH}$ " What do you mean, "correlate," "react"? Is there something happening to them that is quantified? Lines $80-84$ : "MBT05Me, Index $1, \mathrm{Ri} / \mathrm{b}$ " Are you sure that all readers of your paper know what is this? I don't know,

Interactive comment
Printer-friendly version

Discussion paper

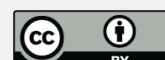


for example. Line 115: “Fig. 1.A)." I don't see Siberia on this map. Lines 120-121: "from the Siberian Oblast of Irkoustsk, Russia" No such administrative or geographical district in Russia. Line 129: cyperaceae should be Cyperaceae Lines 136-138: Strange choice of locations: both do not belong to the Mongolian plateau Line 147: "the geography is characterized by the Baikal lake basin" What do you mean? Line 153: The dark-taiga cannot be dominated by larches (Larix sibirica). Larch is dominant of light taiga. Line 164: Here should be references concerning vegetation description. Line 165: "2.3 Bioclimate Systems" Do you mean 'climate'? Lines 174-175: "Mongolian summer precipitations are controlled by the East Asian Summer Monsoon system (EASM) instead of the Westerlies'. Please provide references that in Northern Mongolia and the Altai Mountains are the summer precipitation controlled by EASM. I think it is not correct and even your Fig. 2 supports this. Line 206: "3.2 SIG Bioclimatic Data". What is SIG? Line 245: "Statistical Analyses", but in lines 227-244 was also statistical analysis. Line 260, 279: "Siberian basin" is absent on the geographical map. Lines 263-264: Fig 5 appears before Fig 4. Lines 313-314: This information about IsoGDGTs you can move to the part when you describe the brGDGTs in the introduction Line 350: What is NSSM? This paper is going to publish in a journal with a wide readership. You have to explain specific terms. Line 367: Fig. 8, appears before Fig. 7 Line 403: "the Siberian-Mongolian system seems to be mainly controlled by precipitation". I just want to emphasize that Siberia has a huge size and varied landscapes. Lines 480: There is not Baikal basin on the geographical map. Baikal is divided into three basins, but it is about the lake. Lines 498, Fig. 9: NSMDB - wrong name Fig. 9: Negative values of MAP should be explained. Fig. 10. The chronological curve is filled only up to $5000 \mathrm{yr}$ BP. Remove the blank part up to $6000 \mathrm{yr}$ BP.

Interactive comment on Clim. Past Discuss., https://doi.org/10.5194/cp-2020-154, 2020.

Interactive comment 